\title{
La construcción de hechos en el discurso jurídico: Análisis del caso de los "robos en cajeros automáticos en la ciudad de Barcelona".
}

\author{
Jenny Cubells Serra \& Lupicinio Iñiguez-Rueda \\ Universitat Autònoma de Barcelona. \\ Departament de Psicología Social
}

\section{RESUMEN}

En este artículo mostraremos cómo los "hechos" considerados "brutos" por la institución jurídica adquieren materialidad y estatuto de "hecho jurídico" a partir de las prácticas que se desarrollan en el seno de la propia comunidad. El análisis realizado revela que los 'hechos brutos' son el resultado de un proceso de construcción discursiva. No existe una manera objetiva de describir hechos, de modo que es falaz sostener el acceso a los mismos ‘tal y como éstos ocurrieron”. Así, la única forma de acercarse a los hechos es a través de un proceso de re-construcción que se realiza mediante prácticas lingüísticas.

Con la finalidad de hacer visible el proceso de materialización de los hechos en el ámbito jurídico, analizaremos algunos documentos extraídos del expediente de un caso de robo con intimidación juzgado en la Audiencia Provincial de Barcelona.

Palabras clave: Discurso jurídico, análisis del discurso jurídico, práctica social, retórica. 


\title{
Constructing facts in legal discourse: Analysing the case of "Robbery on cash-dispenser in the city of Barcelona".
}

\begin{abstract}
This paper will show how the "facts" considered "raw" by the legal institution acquire materiality and status of "legal fact" from the practices that take place within the community itself. The analysis reveals that the 'raw facts' are the result of a process of discursive construction. There is no objective way to describe facts, so it is fallacious to sustain access to the same "as they occurred". So, the only way to move closer to the facts is through a process of re-construction that is done through practical linguistics. In order to make visible the process of construction of the facts in the legal field, we analyze some documents extracted from the file of a case of robbery with intimidation tried in the Provincial Court of Barcelona.
\end{abstract}

Keywords: Legal discourse, analysis of the legal discourse, social practice, rhetoric.

"Lo que parece verdad cuenta mucho más que lo que es verdad, de ahí la búsqueda sistemática de pruebas y técnicas adecuadas para mostrar la verosimilitud de las tesis" (Montara, 1988).

\section{Introducción}

En Derecho los conceptos de objetividad y verdad toman especial relevancia en tanto que la administración de justicia se nos presenta como objetiva e imparcial en el descubrimiento de la "verdad" sobre los hechos juzgados. El hermetismo característico del discurso jurídico obedece a esta necesidad de preservar y comunicar uno de los principales valores del Derecho, a saber; la equidad y/o justicia. El discurso Jurídico cumple una importante función para la construcción de esta objetividad e imparcialidad que pretende la Institución jurídica. La existencia de acuerdos propios de la disciplina, como el sentido y el valor atribuido a las normas jurídicas o el consenso sobre lo que se 
considera un hecho, una presunción o una verdad, junto con el uso de estrategias retóricas parecen no dejar ninguna fisura abierta en este sistema que se nos presenta -en su forma y su contenido- formal y objetivo.

Nuestra lectura sobre la práctica jurídica parte de dos planteamientos teoricometodológicos importantes: la importancia atribuida a la comprensión de los significados compartidos por la comunidad jurídica y la aportación de Austin (1962) que implica considerar el lenguaje como una forma de acción que produce efectos.

De esta forma, consideramos como un efecto del discurso la construcción de los hechos llevada a cabo por los agentes jurídicos que participan de la práctica jurídica. En este artículo mostraremos cómo los "hechos" considerados "brutos" por la institución adquieren materialidad y estatuto de hecho jurídico a partir de las prácticas que se desarrollan en el seno de la comunidad jurídica. Así, la construcción de los hechos se nos presenta como inseparable de la actividad que se realiza a través del habla y los textos (Potter, J. 1998) .

\section{Un enfoque desde los Estudios del Discurso}

Este estudio recoge aportaciones de diferentes perspectivas o tradiciones teóricas; del socioconstruccionismo (Ibáñez, T. 2001), la idea de que la realidad es una producción de la acción social. . Recoge también la influencia de distintas perspectivas dentro de los Estudios del Discurso (Antaki, Ch. 1998; Antaki, Ch. y Iñiguez, L. 1998; Bajtin, M. 1982; Billig, M. 1987, 1988, 1991; Fairclough, N. 1992; Foucault, M. 1969; Van Dijk, 1997) y especialmente se nutre de las aportaciones de los estudios realizados sobre el discurso jurídico. Perelman, Ch. \& Olbrechts-Tyteca, L. (1989), Perelman, Ch. (1980) inspiran el análisis retórico del estudio que muestra las estrategias retóricas que utilizan los agentes jurídicos con el objetivo de persuadir y convencer al tribunal de su versión de los hechos en el marco de una retórica de la verdad. Calvo J. (1993) orienta nuestra mirada en la búsqueda de la coherencia narrativa como elemento fundamental para la construcción de la credibilidad de las narraciones que defienden los agentes jurídicos en el proceso penal. Potter, J. (1998), Wetherell, M. y Potter, J. (1989, 1992) aportan el 
concepto de repertorio interpretativo que nos permite analizar la forma en que los agentes jurídicos construyen sus versiones de los hechos al tiempo que se evidencian algunas de las principales características del Discurso Jurídico. Así mismo, Shuy, R. (1995) hace hincapié en la influencia de los factores lingüísticos y las relaciones de poder, que emergen de las interacciones en el ámbito jurídico, sobre la propia práctica jurídica. En definitiva estos autores nos facilitan la "caja de herramientas" que utilizamos en este estudio. En efecto, tal y como señalara Van Dijk (1997), los estudios del discurso son hoy día una ambiciosa empresa de carácter transdisciplinar que comprende teorías y formas de análisis distintas y que atraviesan multitud de disciplinas de las humanidades y las ciencias sociales. Como dice Van Dijk (2003), esta empresa “no sólo incluye 'análisis', sino también 'teorías', 'aplicaciones', 'crítica' y otras dimensiones de investigación en el campo académico" (2003:12), razones por las cuales nuestro trabajo habría de incluirse dentro de dichos estudios.

El objeto de este análisis es el discurso jurídico. Existen gran variedad de definiciones del término discurso que van desde su concepción en tanto que 'enunciado' hasta la de ‘ideología’ (Iñiguez, L. 2003). Por nuestra parte, en este trabajo entendemos el discurso como una práctica social constitutiva y generadora de realidades y relaciones sociales (Foucault, M. 1969), es decir, que los discursos no sólo reflejan o representan entidades sociales y relaciones, sino que éstos las construyen y las constituyen (Fairclough, N. 1992). Optamos entonces por la siguiente definición:

Un discurso es un conjunto de prácticas lingüísticas que mantienen y promueven ciertas relaciones sociales. El análisis consiste en estudiar cómo estas prácticas actúan en el presente manteniendo y promoviendo estas relaciones: es sacar a la luz el poder del lenguaje como una práctica constituyente y regulativa. (Iñiguez, L y Antaki, Ch. 1994:63).

El interés de este trabajo se centra particularmente en los efectos del discurso jurídico y más concretamente en la construcción de los hechos y la construcción de la objetividad e imparcialidad de los procedimientos jurídicos. El análisis se focaliza en tres núcleos: a) la forma en que se produce o socava la credibilidad de los/as autores/as de una descripción a partir del análisis reórico de documentos jurídicos y la localización y descripción de repertorios interpretativos; b) la intertextualidad como una forma de

Revista Española de Investigación Criminológica 
construir la coherencia narrativa de las versiones producidas por los agentes jurídicos; y c) el proceso de externalización a través del cual las descripciones se presentan como independientes del/la autor/a que las ha producido gracias a la utilización de determinadas formas gramaticales.

\section{El corpus}

El trabajo que presentamos resulta de, y es posible por, una etnografía realizada por uno de nosotros en un bufete de abogados penalistas (Cubells, J. 2002). La elección de la etnografía como forma de acercamiento a la comunidad jurídica ha venido motivada por el interés en los significados compartidos por sus miembros (Sánchez-Candamio, M. 1995; Parnell, P.C., 2002; Kidder, R., 2002).

La etnografía se desarrolló en un gabinete jurídico situado en la ciudad de Barcelona desde el 12/7/95 al 30/5/96. La colaboración del letrado y su equipo posibilitó el acceso a diversos espacios jurídicos catalanes en los que se realizaron las observaciones: juzgados, Audiencia Provincial, gabinetes jurídicos, centros penitenciarios, comisarías, despachos de los agentes jurídicos, ruedas de reconocimiento y un largo etcétera. La información recopilada en este estudio se concreta en la redacción de un Diario de Campo de 210 paginas, las entrevistas realizadas a diversos agentes jurídicos (2 detenidos y sus parejas, 1 letrada de Barcelona, 1 Fiscal, 1 policía judicial, 2 magistrados de instrucción, 1 magistrado de los Juzgados de lo Penal y 1 magistrado de la Audiencia Provincial de Barcelona) y el expediente jurídico del caso de "robo con intimidación" juzgado por la Audiencia Provincial de Barcelona en Julio de 1995. Concretamente se analizarán los siguientes documentos: Doc 1. Comparecencia, Doc. 2. Recurso de Casación, Doc. 3. Respuesta al Recurso de Casación, Doc. 4. Respuesta e la defensa al escrito de casación del Ministerio Fiscal, Doc 5. Escrito de Calificación del Ministerio Fiscal, La selección de los documentos para el análisis ha venido motivada por la posibilidad que nos brindan de conocer la primera narración sobre los hechos así como el diálogo entre las partes implicadas, y las principales características del discurso jurídico entre las que cabe destacar las siguientes: el uso de un repertorio empirista, la preferencia por un estilo narrativo y el uso de un estilo monológico.

Revista Española de Investigación Criminológica

Artículo 4, Número 6 (2008) $\quad$ www.criminología.net

ISSN: $1696-9219$ 


\section{Narrar "hechos"}

En la argumentación un hecho se caracteriza por ser el resultado de una determinada representación de la realidad -que solo puede ser una- e implica la asunción del acuerdo del auditorio universal respecto a los mismos. Sin embargo, en Derecho los hechos están vinculados a las exigencias propias de la disciplina (Perelman, Ch. y OlbrechtsTyteca, L. 1989). En el ámbito del Derecho, el hecho está relacionado con una norma jurídica en tanto que ésta es una regla que establece las consecuencias jurídicas que siguen a un hecho. Así, “si se da el hecho F entonces se darán las consecuencias C. La relación 'si ... entonces ....' significa la relación normativa impuesta por la norma jurídica.” (Wrobleski, J. 1989:192). O, en palabras de Calvo, J. (1993), “la norma (premisa mayor) funciona, pues, como criterio reductor o esquema dogmático de contención de los hechos (premisa menor), permitiendo su puntualización objetiva, para desde allí prescribir -pre-escribir- por subsunción la hipotética conclusión lógicamente deducible” (Calvo, J. 1993:25).

Este planteamiento es claro cuando nos referimos a los "hechos jurídicos". Sin embargo, no ocurre lo mismo con los "hechos brutos", es decir, los hechos denunciados o alegados pendientes aún de calificación, valoración y aplicación de la norma jurídica. En efecto, no resulta fácil la calificación de un hecho bruto determinado a la luz de las normas jurídicas, lo cual implica la existencia de "zonas de penumbra" donde la incertidumbre obedece al conflicto entre interpretaciones diferentes respecto a los "hechos jurídicos". La idea básica es que la comprensión del "hecho" facilitará la posterior calificación, valoración y aplicación de la norma. De esta manera, se recurre a la comprensión narrativa, lo que implica presentar los hechos como historias que son narradas dejando de lado la articulación de las relaciones entre los "hechos brutos" y el derecho. De aquí la idea sostenida en este trabajo referente a que en Derecho importa más el discurso de los hechos que éstos en sí mismos. Esto es así en tanto que el criterio utilizado para determinar la veracidad de las versiones es la coherencia, y ésta es siempre construida en el discurso de los hechos. 
Analizaremos ahora los documentos iniciales del proceso, el que se deriva de la comparecencia, el de la remisión de la denuncia al juzgado y el auto de incoación.

\section{Comparecencia ${ }^{1}$}

Nos interesa conocer cómo se acuerda la existencia de un hecho bruto y cómo éste se convierte en un hecho jurídico a lo largo del proceso penal. El caso que nos ocupa se inicia con la denuncia de una mujer que se presenta en Comisaría exponiendo lo que le sucedió mientras operaba en un cajero automático en la ciudad de Barcelona. En la misma época se recogen en varias comisarías de la ciudad otras denuncias similares a la que ahora vamos a analizar.

La estructura de la denuncia es la misma en todos los casos, el Fragmento 1 nos sitúa en el escenario en que se desarrolla la acción haciendo referencia a un lugar y a una hora determinados. Acto seguido se presenta a los funcionarios que recogen la denuncia (Fragmento 2):

\section{Fragmento 1}

“En Barcelona, y en la Comisaría de Distrito del Cuerpo Nacional de Policía de Sur, siendo las 20:42 horas del día 07-02-1994. (Doc. 1 Comparecencia).

\section{Fragmento 2}

Ante los Funcionarios del referido Cuerpo con categorías de Inspector Jefe y Policía, y carnets profesionales números 12569 y 73544, habilitados respectivamente como Instructor y secretario para la práctica de las presentes. (Doc. 1 Comparecencia)

Que la Comparecencia se inicie construyendo el contexto no es casual. En efecto, el documento analizado recurre al repertorio interpretativo que denominaremos "repertorio empirista" para construir la credibilidad en la narración de los hechos. El concepto de repertorio interpretativo propuesto por Potter, J y Wetherell, M. (1989) hace referencia a

\footnotetext{
${ }^{1}$ Comparecencia: Acción y efecto de comparecer. Comparecer: Presentarse ante una autoridad u otra persona.
}

Revista Española de Investigación Criminológica

Artículo 4, Número 6 (2008) $\quad$ www.criminología.net

ISSN: $1696-9219$ 
los recursos que las personas utilizamos con la finalidad de construir determinadas versiones de los hechos.

El repertorio empirista se caracteriza por: a) presentar los hechos como si fueran "datos primarios" otorgándoles existencia "real" con independencia de la intervención humana; b) la utilización de formas gramaticales que minimizan las acciones de los autores; y c) la exposición de normas y rutinas que conforman el procedimiento jurídico.

En el documento que nos ocupa, observamos las características citadas. En efecto, la identificación de los funcionarios evita la más mínima referencia a su persona presentándolos como una "posición”, en este caso Funcionarios con un determinado cargo y con un número de identificación como si éstos carecieran de nombre, a diferencia de la denunciante que además de su número de DNI aparece con su nombre completo (Fragmento 3):

\section{Fragmento 3}

COMPARECE/N: En calidad de denunciante C.M.C., con d.n.i. número XXXX, domiciliado en la calle XXX Barcelona, teléfono XXX, nacido el día XXX en Barcelona hijo de XXXX. (Doc. 2 Comparecencia).

La presentación de los funcionarios que reciben la denuncia y la contextualización del acto de comparecencia producen ciertos efectos: (a) es la voz de la Institución la que se escucha en tanto que se hace desaparecer las personas que la componen haciendo constar en su lugar las posiciones asignadas por la propia Institución; (b) esta estrategia persigue conferir una mayor credibilidad al acto que se lleva a cabo al revestirlo de objetividad puesto que la subjetividad inherente a la actividad humana parece, y sólo parece, haber desaparecido con la desaparición, valga la redundancia, de las "personas"; y (c) las referencias a la fecha, hora, y localización de la denuncia, así como su contenido facilita la atribución futura de varias denuncias similares al mismo presunto delincuente. Como exponía el miembro de la policía judicial en su entrevista (EPJ, 96), el "modus operandi" 2 y otros datos son recogidos en la comparecencia con la

\footnotetext{
${ }^{2}$ El "modus operandi" hace referencia a la conducta del autor/a del delito en la comisión del mismo. Se puede concretar en el uso de un arma en concreto, la utilización de un método de
}

Revista Española de Investigación Criminológica

Artículo 4, Número 6 (2008) $\quad$ www.criminología.net

ISSN: $1696-9219$ 
expectativa de inferir la presunta autoría en un determinado delito basándose en los elementos comunes que presentan las denuncias tomadas en diferentes comisarías de policía.

De esta forma, en la comparecencia a través de la externalización de los agentes que participan del proceso "Funcionarios del referido Cuerpo con categorías de Inspector Jefe y Policía, y carnets profesionales números 12569 y 73544, habilitados respectivamente como Instructor y secretario para la práctica de las presentes" y la utilización de un lenguaje técnico y pretendidamente neutral: "habilitados respectivamente para la práctica", "comparecencia", "comparecen”, "en calidad de denunciante", etc... se ha construido la credibilidad del acto que ha de materializar la versión de los hechos que aportará la denunciante. En el Fragmento 4 se presentan los hechos denunciados como "reales" presentándolos como "hechos brutos" al situarlos en un lugar y un tiempo determinados:

Fragmento 4

Y MANIFIESTA: que el día 4 de febrero de 1994 y siendo las 19.08 horas, cuando se encontraba en el cajero automático, sito en la confluencia de la calle Rocafort con Gran Vía de las Cortes Catalanas, de la Caixa de Barcelona, con fin de sacar dinero, un individuo se le acerca por la espalda e intimidándola con una jeringuilla usada, le dice que no grite y hiciera todo lo que le fuese diciendo si no la pincharía. Que le solicita a la dicente que efectúe una extracción de CINCUENTA MIL PESETAS, la cual realiza, solicitando a su vez que le entrege el dinero con discreción y que acompañe al citado individuo a la calle, el cual en todo momento intimidando, comienzan a andar Gran Via de Cortes catalanas dirección c/Entenza, en el transcurso la obliga a parar un taxi, y a subir al mismo, mencionando en voz baja, que disimulara para que el taxista no se percatara de la acción, parando el taxi, por requerimiento del individuo en Plaza Universidad, haciendo bajar al dicente. Que una vez bajado del vehiculo

huida, el discurso que pone en marcha en la interacción con la víctima, la actuación en una zona o zonas determinadas, etc... 
ignora dirección de huida. Que la características del individuo son las siguientes; 1.80 m., moreno, delgado, pelo negro y corto, vistiendo un pantalón tejano, y una chaqueta de piel corta de color negro. Que quiere hacer constar que en todo momento era intimidada por el individuo. Y no teniendo nada mas que manifestar firman la presente en señal de conformidad con lo en ella escrito, en unión del Instructor de lo que como Secretario CERTIFICO. (Documento 1. Comparecencia).3

La comparecencia supone una primera materialización de una versión puesto que a partir de la versión de la denunciante se construye una narración que toma la forma de documento legal en el expediente jurídico del caso. Sin embargo, la narración de los hechos que aparece en el escrito no corresponde a la declaración literal de la dicente como la denominan en el texto- sino que la versión está escrita en el más puro estilo jurídico, es decir, recurriendo al repertorio empirista. Este estilo cumple una función determinada, construir la objetividad que dará credibilidad a la versión El autor hace uso de diversas fórmulas que tratan de hacer desaparecer al autor del texto traspasando la responsabilidad de la narración a la denunciante: "Y MANIFIESTA”, "Que quiere hacer constar...”, “que solicita a la dicente ....”, etc. De esta manera, mediante el discurso se construye la posición del autor como "neutral" en tanto que la narración pretende la no realización de juicios de valor sobre la denuncia.

Si se revisan otras comparecencias observamos similitudes en la estructura y los datos aportados en tanto que la redacción del texto se realiza siguiendo un protocolo. Por tanto, podemos afirmar que la redacción del documento produce una narración que recoge aquellos datos que la Institución considera relevantes para la materialización del hecho, es decir, supone una primera construcción del hecho a cargo de la Institución Jurídica. El uso de los detalles en la narración construye un discurso realista, como señala Potter (1998): “(...) el discurso realista obtiene su sentido de una secuencia simple de descripciones de objetos y sucesos" (Potter, J. 1998:208). Efectivamente, la comparecencia nos ofrece una descripción detallada de los hechos que le sucedieron a la

\footnotetext{
${ }^{3}$ Los textos extraídos del expediente jurídico están copiados literalmente respetando incluso las faltas de ortografía.
}

Revista Española de Investigación Criminológica

Artículo 4, Número 6 (2008) $\quad$ www.criminología.net

ISSN: $1696-9219$ 
denunciante, ubicación geográfica, secuencia detallada de acciones, y descripción física del atacante.

Este tipo de narración favorece adoptar la posición de la persona que vivió el suceso, facilita a su vez la aceptación de su punto de vista y acredita a la dicente como testigo puesto que, como dice Potter, "una manera de obtener la categoría de testigo consiste en proporcionar descripciones gráficas y vividas. Éstos son los tipos de descripciones que se pueden derivar de un examen cuidadoso de una escena, y pueden tener características que pueden parecer difíciles de inventar a causa de su especificidad o, quizá, de su extrañeza” (Potter, J. 1998:211).

Los detalles aportados en el presente documento se refieren a los hechos acaecidos mientras que se obvia la más mínima referencia a las emociones que suelen provocar este tipo de situaciones a la víctima. La ausencia de referencias a los aspectos emotivos en el documento que analizamos obedece, por un lado, a la intención de crear un discurso objetivo carente de la subjetividad atribuida a las emociones, y por otro lado, permite ofrecer una narración descriptiva centrada únicamente en el "hecho", es decir, obedece a la intención de construir el "hecho" que, al fin y al cabo es lo que a lo largo del proceso penal, se ha de juzgar.

\section{Construir la objetividad y Materializar los hechos}

La decisión jurídica final emitida por el Tribunal se da tras valorar las versiones rivales sobre los hechos que aportan las partes en el proceso penal. Así, el proceso penal toma la forma de enfrentamiento entre las partes de tal manera que se establece una relación dialógica en la que cada parte aporta sus argumentaciones basándose en una estrategia previamente diseñada.

El escrito de Calificación del Ministerio Fiscal solicita la apertura del juicio oral aportando su versión de los hechos. Este escrito, al igual que el resto de escritos de calificación de las partes, realiza las siguientes acciones: 
a. Aportan su propia versión de los hechos presentándolos como "hechos brutos". Como puede verse en el Fragmento 9, el Fiscal presenta la motivación, el instrumento y las acciones presuntamente realizadas por el acusado y localizadas, como hechos fechados:

Fragmento 9.

EL FISCAL, despachando el trámite previsto en el artículo 790 de la Ley de Enjuiciamineto Criminal, solicita la apertura del Juicio Oral ante el JUZGADO DE LO PENAL, formulando Escrito de Acusación respecta a F.M.S, en base a las siguientes CONCLUSIONES PROVISIONALES:

1'.- El acusado, F.M.S, mayor de edad y sin antecedentes penales, movido por el afán de procurarse un beneficio patrimonial y valiéndose de una jeringuilla hipodérmica realizó los hechos siguientes:

Sobre las 19:08 horas del día 4 de febrero de 1.994, se dirigió al cajero automático instalado en la sucursal de "La Caixa" sito en la confluencia de la calle Rocafort con la Gran Vía de esta Ciudad, y concominando con la jeringuilla a C.M.C, la obligó a que extrajera 50.000 pts.

Una vez con el dinero en su poder, el acusado le exigió que anduviese junto a él por la calle Entenza y que subiera con él en un taxi, advirtiéndole que disimulase para que el taxista no se diera cuenta de que la tenía amenazada. Al llegar el taxi a la Pza. Universidad, el acusado se apeó dándose a la fuga.

Sobre las 18:49 horas del día 17 del mismo mes, el acusado advirtiendo a R.V.P que portaba una jeringuilla con restos de sangre con la que podía transmitirle el S.I.D.A. la obligó a que extrajera del cajero automático instalado en la sucursal de "La Caixa” de la calle Bailén, 19 de esta ciudad, 50.000 pts, dándose a la fuga. 
A las 9:00 horas del siguiente día 18, penetró en la zona destinada a cajero automático en la oficina de "La Caixa" de la calle Independencia, 363, y exhibiendo una jeringuilla a I: S.P, logró apoderarse de 2.000 pts.

Quince minutos más tarde, en otro cajero instalado en otra sucursal, sita en el cruce delas calles Rosellón y Dos de Mayo, por el mismo procedimiento se apoderó de 20.000 ptsde M.A.V.M.

A las 17:00 horas del mismo día, penetró en la sucursal de "La Caixa" sita en el número 275 de la calle Pujadas, y advirtiendo a M.C.V.C que portaba una jeringuilla y sufría del S.I.D.A,. le exigió que sacara 50.000 pts de su cuenta, y a pesar de su insistencia, la víctima logró salir del recinto y refugiarse en una tienda cercana, desistiendo el acusado de su acción.

Media hora más tarde, lo intentó de nuevo, en el mismo cajero, con M.M.F y colocando a la hija de corta edad que le acompañaba una jeringa en el brazo, le exigió le entregara 42.000 pts, dándose acto seguido a la fuga. (Documento 5. Escrito de Calificación del Ministerio Fiscal).

En la narración del Fiscal los hechos son narrados como una historia donde el vínculo entre los diferentes episodios es la figura del autor de los mismos. Estamos pues ante una narración con "protagonista". En este sentido la narración del Fiscal toma la forma de biografía de F.M.S. En el fragmento 9 se establece una relación de causalidad entre el modus operandi y la intención que le atribuye al acusado. El recurso retórico utilizado por el Fiscal está fundamentado en la denominada por Perelman, Ch. y Olbrechts-Tyteca, L (1989) “estructura de lo real”. De esta manera se establece una relación de solidaridad entre los juicios admitidos -los hechos descritos- y el que se intenta promover -intención de beneficiarse del patrimonio de las víctimas-.

A partir de inferir las intenciones del mismo se construye la coherencia de lo acaecido en un relato que recurre al uso de las "figuras de presencia" (Perelman, Ch. y OlbrechtsTyteca, L. , 1989). Este recurso se basa en la selección de los datos presentados, de tal manera que se repite en cada delito la descripción una determinada manera de proceder -modus operandi-. El recurso produce el efecto de construir: (a) la familiaridad con los 
hechos descritos en tanto que comparten aspectos comunes; y (b) la asociación entre el modus operandi y la identidad del presunto autor de los hechos. Esta asociación es construida en el relato del Fiscal en tanto que el nexo de unión entre los diferentes delitos denunciados es la persona del detenido.

b. Convierten los "hechos brutos" en "hechos jurídicos" al relacionar los primeros con las normas jurídicas. Como puede verse en el Fragmento 10, los hechos son calificados como 'robo con intimidación' citando el Código Penal:

Fragmento 10.

$2^{a}$.- Los hechos relatados constituyen:

Los descritos con letras A), B), C), D), y F) sendos delitos de ROBO CON INTIMIDACIÓN con empleo de instrumento peligroso de los artículos 500 y $501.5^{\circ}$ y último párrafo del Código Penal. Y el descrito con la letra E) una tentativa de dicho delito.

3a.- Es AUTOR el acusado

$4^{a}$.- No concurren circunstancias modificativas. (Documento5. Escrito de Calificación del Ministerio Fiscal).

En definitiva la construcción de los "hechos jurídicos" requiere ciertas operaciones: (a) conseguir a través de la utilización de ciertos recursos retóricos (figuras de presencia, estructura de lo real, etc) la adhesión del auditorio a la versión presentada por el Fiscal sobre los hechos acaecidos; (b) en relación al punto anterior, el Fiscal propondrá las pruebas que apoyan la versión de los hechos que presenta en su escrito y que a su vez serán utilizadas para la justificación de sus conclusiones finales; y (c) la aplicación de la norma que funciona como esquema dogmático a través del cual los hechos son interpretados. La aplicación de la norma implica por tanto un proceso de categorización a través del cual los hechos son "tipificados". 
c. Solicitan las consecuencias que, en su criterio, deben seguirse de la comisión de un hecho delictivo, es decir, solicitan una pena determinada, en este caso las penas de prisión (Fragmento 11):

Fragmento 11.

5'.- Procede imponer al acusado las penas de CINCO AÑOS DE PRISIÓN MENOR por cada delito consumado, con la limitación del artículo $70.2^{a}$ del Código Penal, en cuanto al cumplimiento de tiempo real de privación de libertad en centro penitenciario, y UN AÑO DE PRISIÓN MENOR por el delito intentado. Accesorias y costas.

RESPONSABILIDAD CIVIL.- El acusado deberá ser condenado a restituir las siguientes cantidades a las personas que se relacionan a continuación: (...). (Documento 5. Escrito de Calificación del Ministerio Fiscal).

d. Proponen las pruebas que han de ser practicadas en el juicio y a partir de las cuales emiten conclusión (Fragmento 12):

Fragmento 12.

OTROSI I) Para el acto de Juicio Oral este Ministerio propone la siguiente PRUEBA:

Examen por el Tribunal y las partes de la ropa ocupada en la Entrada y registro del domicilio del acusado. (Folios 43 y38).

Interrogatorio del acusado 
TESTIFICAL, con examen de los siguientes testigos, cuya citación, de conformidad con el artículo 790.5 de la Ley de Enjuiciamiento Criminal, debe hacerse por medio de la oficina judicial: (nombres de las víctimas)

PERICIAL: Dr. F.J.G.O, a fin de que tras el examen del acusado, dictamine e informe al Tribunal del grado de imputabilidad del acusado derivado de la drogodependencia que el mismo refiere.

DOCUMENTAL de los folios 2, 13, 27, 37, 38, 43, 44, 51, 56, 57, 65, 69, 104, $113,118,122,127,136,137,143,144,152,153,156,157,182$ y 183 la cual deberá practicarse en las sesiones del Juicio Oral por medio de la íntegra lectura de los mismos, salvo que la defensa del acusado, por entenderse informada de su contenido, renuncie a ella expresamente de los cuales se tomará oportuna nota en el acta, y todo ello sin perjuicio de la obligación impuesta al órgano judicial en el Art. 726 de L.E.Cr.

Más documental, con visionado de las grabaciones de los hechos $A, B, C, D, y$ E, realizados en vídeo por la entidad Caixa d'Estalvis i Pensions de Barcelona, a cuyo Departamento de Seguridad deberá requerirse a fin de que los aporte a Juicio, aportando el magnestoscopio y televisor esta Fiscalía.

OTROSI II) Se interesa mantener la actual situación personal del acusado. (Documento5. Escrito de Calificación del Ministerio Fiscal).

La narración en forma de biografía permite: (a) hilvanar los hechos presentados con las conclusiones posteriores; y (b) narrar los hechos atribuyendo su autoría con absoluta rotundidad al detenido, o evitando la fórmula "presunto autor" en tanto que aún no demostrada, es coherente con la conclusión aportada: " $3^{a}$ Es AUTOR el acusado".

Así mismo la ausencia de referencias a la drogadicción y posible insanía mental del acusado -argumentos esgrimidos por la defensa- favorece la emisión como conclusión de la no pertinencia de valorar posibles circunstancias atenuantes de la pena que 
pudieran derivarse de considerar que éste no estaba capacitado mentalmente en el momento de los hechos.

La omisión en el presente documento de los aspectos que acabamos de nombrar es resultado de: (a) la posición del Ministerio Fiscal que parece considerar que la posible insania mental del acusado responde antes a una estrategia de la parte contraria para construir la atenuante que a la correspondencia con la realidad; (b) el estilo monológico del escrito que se concreta en la presentación de las argumentaciones coherentes con las conclusiones emitidas dejando de lado las informaciones contrarias; y (c) la intención de reforzar el efecto de presencia construido en la presentación de los datos obviando informaciones incompatibles. Efectivamente, la atribución de intención y "modus operandi" al acusado evidencia un cierto grado de planificación de las acciones incompatible con la tesis de falta de control de los "frenos inhibitorios" que podrían derivarse de la drogadicción y la insania mental.

Los hechos adquirirán materialidad a través de un procedimiento cuidadosamente estipulado por la Institución -“Testifical”, 'pericial' "documental”- el cual, a su vez, se basa en los principios del método científico y que se concreta en la aportación de "pruebas váildas". Para que una determinada práctica ostente el valor de "prueba válida" en el proceso penal debe cumplir ciertos requisitos como ser considerada objetiva y eficaz para la función que se le atribuye.

Esta objetividad es construida discursivamente, como se desprende del análisis del fragmento 12, mediante citas de autoridad:

"PERICIAL: Dr. F.J.G.O, a fin de que tras el examen del acusado, dictamine e informe al Tribunal del grado de imputabilidad del acusado derivado de la drogodependencia que el mismo refiere"

pruebas de evidencia "empírica":

“Examen por el Tribunal y las partes de la ropa ocupada en la Entrada y registro del domicilio del acusado. (Folios 43 y38)" 
"Más documental, con visionado de las grabaciones de los hechos $A, B, C, D, y E$, realizados en vídeo por la entidad Caixa d'Estalvis i Pensions de Barcelona, a cuyo Departamento de Seguridad deberá requerirse a fin de que los aporte a Juicio, aportando el magnestoscopio y televisor esta Fiscalía”

y la descripción de normas y rutinas que confieren rigurosidad, objetividad e imparcialidad al procedimiento jurídico:

"TESTIFICAL, con examen de los siguientes testigos, cuya citación, de conformidad con el artículo 790.5 de la Ley de Enjuiciamiento Criminal, debe hacerse por medio de la oficina judicial: (nombres de las víctimas)”

“DOCUMENTAL de los folios 2, 13, 27, 37, 38, 43, 44, 51, 56, 57, 65, 69, 104, 113, $118,122,127,136,137,143,144,152,153,156,157,182$ y 183 la cual deberá practicarse en las sesiones del Juicio Oral por medio de la íntegra lectura de los mismos, salvo que la defensa del acusado, por entenderse informada de su contenido, renuncie a ella expresamente de los cuales se tomará oportuna nota en el acta, y todo ello sin perjuicio de la obligación impuesta al órgano judicial en el Art. 726 de L.E.Cr."

Así, la Institución construirá la objetividad de la actividad probatoria recurriendo a la autoridad que confiere el conocimiento científico aceptado en nuestra sociedad como valuarte de la objetividad, esto es, como la única posibilidad de alcanzar la "verdad" de lo sucedido

\section{Discusión}

En este trabajo hemos considerado la práctica jurídica y el ejercicio del Derecho como una práctica social donde la argumentación es una de sus características principales. Como revela nuestro análisis, y a la luz de este enfoque, los criterios de objetividad e imparcialidad que pretende el Derecho han sido cuestionados. 
En efecto, los 'hechos brutos' que se pretenden juzgar resultan de un proceso de construcción discursiva. No existe una manera objetiva de describir hechos, de modo que es falaz sostener el acceso a los mismos 'tal y como fueron' dado que la única forma de acercarse a ellos es mediante el proceso de re-construcción desde el presente de algo que ocurrió en el pasado. Esta re-construcción se realiza mediante prácticas lingüísticas.

Además de la construcción de hechos brutos, hemos descrito la operación de su conversión en hechos jurídicos, la creación de pruebas válidas dónde son prioritarios los criterios de la ciencia, y la conclusión final del caso. Así mismo hemos mostrado la primera narración con protagonista que visibiliza la importancia el discurso para la construcción de la coherencia en la versión de los hechos.

En definitiva, en este artículo hemos mostrado que la comunidad jurídica utiliza un estilo narrativo en la redacción de sus documentos. La preferencia de la Institución por este estilo muestra la importancia conferida al discurso de los hechos en tanto que es a través del discurso que se construye la coherencia de los mismos. Por lo tanto, la argumentación presente en los documentos analizados busca convencer al auditorio. Para ello, la Institución recurre al repertorio empirista así como a los argumentos de tipo racional de manera que las argumentaciones utilizadas toman la forma de argumentaciones cuasi-lógicas y basadas en lo real, pretendiendo tomar su fuerza de la razón y de la objetividad.

Perelman, Ch. (1980) establecen una clara diferencia entre lo "racional" y lo "razonable". Lo racional se refiere a las verdades inmutables validadas universalmente, mientras que lo razonable hace referencia a una noción flexible fruto de la actividad humana y como tal influenciada por la historia, la cultura y las tradiciones. (Perelman, Ch. 1980).

En este sentido aceptar que la justicia se basa en lo razonable implica aceptar también que el criterio de "verdad" surge de un acuerdo. Este hecho nos lleva a cuestionar fuertemente el criterio de "verdad" como universal y absoluto en tanto que es fruto de las prácticas sociales. Así, aún cuando el discurso teórico de la ciencia jurídica pretende objetividad emplazando el criterio de verdad fuera de la producción humana, en la 
práctica ésta aparece como un valor relativo, lo cual nos remite nuevamente a la convivencia de dos discursos paralelos; el discurso teórico -lo que debería ser- y el práctico -lo que es-.

De esta manera, en la práctica jurídica el valor de verdad se ve remplazado por el valor de uso en su adecuación a las finalidades o intereses humanos. Efectivamente, a menudo no se trata de que la sentencia emitida por el Tribunal sea correcta, esto es; se corresponda a la realidad, sino que sea ventajosa o útil -valor de uso-.

Remplazar el criterio de verdad por el valor de uso implica asumir la imposibilidad de alcanzar el conocimiento de los hechos acaecidos en el pasado desde el presente. Ya nos hemos referido a este punto anteriormente por lo que no insistiremos. Ahora bien, no poder acceder a los hechos del pasado tal y como ocurrieron no libera a la justicia de la necesidad de justificar las decisiones tomadas por el Tribunal y la correcta aplicación de la Ley. Como expone Lyons:

"Los tribunales han de determinar la manera de aplicar aspectos poco claros de las leyes. Esto último es particularmente importante porque tiene una repercusión sobre las propias leyes. (...) no se limitan a aplicar la ley sino que contribuyen a hacerla. No adjudican, también legislan” (Lyons, 1989:94).

Esta afirmación nos remite al concepto de intertextualidad entendido como la relación de cada discurso con otros discursos afines. Así, la asimilación de nuevos casos con motivo de una decisión judicial, no es únicamente un paso de lo general a lo particular, sino que contribuye al fundamento de la realidad jurídica modificando su significación.

En este sentido podemos afirmar que la Justicia es una construcción social. Efectivamente, en tanto que los hechos y las verdades surgen de acuerdos propios de la disciplina, y en tanto que éstos son fruto de las prácticas sociales, podemos afirmar que constituyen construcciones sociales.

De esta manera, la Justicia aparece como un órgano regulador de los comportamientos de los miembros de la sociedad, acordando lo que es "normal" y lo que no, lo que está prohibido y lo que está permitido y a partir de aquí persigue construir sujetos que no se aparten de esta pretendida "normalidad".

Revista Española de Investigación Criminológica

Artículo 4, Número 6 (2008) $\quad$ www.criminología.net

ISSN: $1696-9219$ 


\section{Referencias}

Aarnio, A. (1987) The rational as Reasonable. Dordrecht: Reidel Publishing Company.

Antaki, Ch. (1998) Analysing Ordinary Explanation: A casebook of methods London: Sage.

Antaki,Ch. E Íñiguez,L. (1998). “Análisis del discurso”. Anthropos, 177:59-66.

Austin, J.L. (1962) Cómo hacer cosas con palabras. Barcelona: Paidós, 1990.

Bajtin, M. (1982) Estética de la creación verbal. Madrid: Siglo XXI. (1998)

Berger, P.; Luckmann, T. (1966) La construcción social de la realidad. Barcelona: Herder, 1988.

Billig, M. (1987) Arguing and thinking. A rethorical approach to social psychology. Cambridge: Cambridge University Press, 1991.

Billig, M. (1988) Ideological Dilemmas. A social Psychology of Everyday Thinking. London: Sage.

Billig, M. (1991) Thinking as arguing In Ideology and opinions. London: Sage.

Calvo, J. (1992) Comunidad Jurídica y experiencia interpretativa. Un modelo de juego intertextual para el derecho. Barcelona: Ariel Derecho.

Calvo, J. (1993) El discurso de los hechos. Madrid: Tecnos.

Calvo, J (1992) “Coherencia narrativa y razonamiento judicial”. Revista Poder Judicial 25: $72-102$

Cubells, J. (2002) La construcción social del delito: un estudio etnográfico en la práctica del Derecho Penal. Tesis Doctoral. Universidad Autónoma de Barcelona, UAB. http://www.tdx.cesca.es/TESIS_UAB/AVAILABLE/TDX-0424103181630/ecs1de5.pdf

Fairclough, N. (1992) Discourse and social Change. Cambridge: Polity Press.

Foucault, M. (1969) La arqueología del saber. Madrid: Siglo XXI, 1990.

Foucault, M. (1970) El orden del discurso. Barcelona: Tusquets editores, 1999.

Foucault, M. (1975) Vigilar y castigar .Madrid: Siglo XXI, 1998.

Foucault, M. (1978) La verdad y las formas jurídicas. Barcelona: Gedisa, 1995.

Gergen,K (1994) Realidades y relaciones: Aproximaciones a la construcción social. Barcelona: Paidos, 1996.

Ibáñez, T. (2001) Psicología social construccionista. México: Universidad de Guadalajara. 
Ibáñez, T. (2002) Municiones para disidentes. Barcelona: Gedisa

Íñiguez,L. (2003). El análisis del discurso en las ciencias sociales. En Íñiguez, L. (Ed.)

Análisis del discurso. Manual para las ciencias sociales (pp.83-123). Barcelona: EDIUOC.

Íñiguez,L. y Antaki,Ch. (1994). El análisis del discurso en Psicología social. Boletín de Psicología, 44:57-75

Kidder , R. (2002) Exploring Legal Culture in Law-Avoidance Societies. In Starr, J; Goodah, M. (Eds.) (2002) Practicing ethnography in Law . New Dialogues, Enduring Methods (pp.87-107). Ed. Palgrave Mcmillan.New York.

Latour, B,; Woolgar, S. (1979) La vida en el laboratorio. La construcción de los hechos científicos. Madrid: Alianza Editorial, 1995.

Lyons, D. (1984) Ética y Derecho. Barcelona: Ariel, 1989.

McCORMICK, J. P. (1999) “Three ways of thinking 'critically' about the law". American Political Science Review, Vol. 93, 2: 413-428.

Parnell, P. (2002) Trekking Processual Planes Beyond the Rule of Law In J.Starr; M.Goodah (Eds.) (2002) Practicing ethnography in Law . New Dialogues, Enduring Methods (pp.34-49). Ed. Palgrave Mcmillan.New York.

Perelman, Ch. (1980) Justice Law and argument. Essays on Moral and Legal Reasoning. Dordrecht: Reidel Publishing Company.

Perelman, Ch.; Olbrechts-Tyteca, L. (1989) Tratado de la argumentación. La nueva retórica. Madrid: Gredos.

Potter, J. (1998) La representación de la realidad. Discurso, retórica y construcción social. Barcelona. Paidós.

Sánchez-Candamio, M. (1995) "La etnografía en psicología social" Revista de Psicología Social Aplicada Vol. 5 1⁄2: 27-40.

Shuy, R.W. (1995) "How a Judge's Voir Dire Can Teach a Jury What to Say". Discourse \& Society, Vol. 6(2): 207-222.

Starr, J; Goodah, M. (Eds.) (2002) Practicing ethnography in Law . New Dialogues, Enduring Methods. New York: Palgrave Mcmillan.

Van Dijk,T. (1997). The study of Discourse. En T.Van Dijk (Ed.) Discourse as Structure and Process. Discourse Studies: A Multidisciplinary Introduction. Volume 1 (pp. 1-134). London: Sage. 
Van Dijk,T. (2003). Prólogo En L.Íñiguez (Ed.) Análisis del discurso. Manual para las ciencias sociales (pp.11-16). Barcelona: EDIUOC.

Wetherell, M \& Potter, J. (1989) Narrative Characters and Accounting for violence.Texts of Identity. London: Sage.

Wetherell, M \& Potter, J. (1992) Mapping the language of racism. discourse and the legitimation of explotation. London: Harvester Wheatsheaf.

Wroblesky, J. (1989) Sentido y hecho en el derecho. Senicio Editorial. Universidad País Vasco. 
Jenny Cubells Serra. Doctora en Psicología. Profesora Lectora del Departamento de Psicología Social de la Universidad Autònoma de Barcelona, UAB. Imparte docencia en la Licenciatura de Criminología de la Universidad Autónoma de Barcelona. Autora de diversas publicaciones relacionadas con la Psicología Jurídica. Actualmente dirige la investigación "Violència de gènere i espais jurídico-penals: imaginaris col.lectius i construcció de subjectivitats".

Lupicinio Iñiguez-Rueda. Doctor en Psicología Social. Catedrático de Psicología Social en el Departament de Psicología Social de la Universitat Autònoma de Barcelona. Miembro del GESCIT (Grup d'Estudis Socials de la Ciencia i la Tecnologia). Editor junto con Tomás Ibáñez de 'Critical social Psychology' (1997, London:Sage) y de 'Análisis del Discurso. Manual para las ciencias sociales' (2003, Barcelona:EDIUOC) 